\title{
Response Surface Analysis and Process Optimization of Non-Cereal (Elephant Foot Yam, Taro and Water Chestnut) Snacks
}

\author{
Anuj Saklani ${ }^{\mathrm{a}}$, Ravinder KaushiK ${ }^{\mathrm{b}}$, And Krishan KumaR ${ }^{\mathrm{c}}$ \\ a School of Bioengineering and Food Technology, Shoolini University, Solan, India, 125001 \\ b School of Health Sciences, University of Petroleum and Energy Studies, Dehradun, Uttrakhand, India, 248001 \\ ${ }^{c}$ Eternal University, Baru Sahib, Sirmor, Himachal Pradesh, India \\ ${ }^{*}$ Corresponding author \\ ravinder_foodtech2007@rediffmail.com \\ TEL.: +91-9416962729
}

Received: 31 January 2019; Published online: 18 October 2021

\begin{abstract}
The present study was conducted to develop non-cereal starch extruded products. The effects of feed moisture (15-21\%), temperature $\left(130-170{ }^{\circ} \mathrm{C}\right)$ and screw speed (120-160 rpm) were evaluated on the physical and functional properties of extruded snacks using response surface methodology. Feed moisture and screw speed increased the bulk density and hardness of extruded snacks. Significant decreases in water absorption index and increases in water solubility index were observed with increases in extrusion temperature. The best conditions were determined by numerical optimization. The optimized value for non-cereal snacks for feed moisture is $18.22 \%$, temperature $155.96{ }^{\circ} \mathrm{C}$, screw speed $142.75 \mathrm{rpm}$ and, desirability is 0.75 . Verification of results showed decent agreement between the responses of experimental values at certain optimum conditions and the predicted values.
\end{abstract}

Keywords: Extruded snacks; Elephant foot yam flour; Taro flour; Water chestnut flour

\section{Introduction}

At present cereal-based extruded products dominate the market, whereas very few noncereal-based extruded products are manufactured (Kaushik et al., 2018). Fasts are a part of life of the Indian population in which noncereal-based foods are consumed. Therefore, the present study will be carried out to develop noncereal starch-based extruded products for fasting individuals and the general population. Extrusion cooking is a multi-technique process that converts extrudate into specific shape, size and highly expanded products. All the unit operations are performed by a single extrusion machine like mixing, kneading, shearing, shaping, form- ing and cooking is optional (Bordoloi \& Ganguly, 2014).

It is an energy efficient, rapid, continuous process and can be used to produce better quality starchy foods including expanded snacks, ready to eat (RTE) cereals, confectioneries, modified starches, baby foods, pasta, pet foods and extruded crisp breads (Deshpande \& Poshadri, 2011). Feed composition, particle size, additives, temperature, feed rate and screw speed affect the pasting, textural, physiochemical and morphological properties of extruded products (Singh et al., 2009). The Indian snack market has been increasing rapidly with an annual growth rate of about 15 to $20 \%$ (Ministry of Food Processing Industries, 2015). High tem- 
perature and short time extrusion (HTST) cooking has many benefits over low temperature and long-time (LTLT) cooking, because of inactivation of anti-nutritional factors and minimal nutritional loss along with production of unique textural properties like crispness and crunchiness (Moreno et al., 2018).

Extruded foods have been recognized to provide nutritious products and combine quality ingredients and nutrients to produce processed foods that contain detailed levels of each required nutrient (Yagci \& Gogus, 2008). Extrusion cooking used in this study was skillful through the application of heat to the blend directly by means of steam inoculation. Frequent changes observed in ingredients through the extrusion cooking process were the gelatinization of starch, destruction of natural toxic ingredients, denaturation of proteins and the diminishing of microbial counts (Balfour et al., 2014).

Parvathi et al. (2016) reported that tubers and edible roots gained third position as human food after cereals and legumes. In several places they also serve as staple foods and sources of cheap energy, especially for the weaker section of the population. Non-cereal-based extruded products were developed using Maori potato flour (Singh et al., 2009). Rodriguez-Miranda et al. (2011) developed taro and maize flour-blended extruded snacks with higher expansion and water solubility indexes. Taro (Colocasia esculenta) is a plant generally cultivated in tropical territories for its underground corms. Taro roots contain an abundance of dietary fiber and starches, biomolecules, magnesium, zinc, phosphorous, potassium, manganese, and copper, and vitamins A, C, E, B6 that are basic for human wellbeing (Anuj Saklani \& Kumar, 2021).

Puffed snacks using Amorphophallus paeoniifolius, Typhonium trilobatum and Colocasia esculenta were prepared by Parvathi et al. (2016) and showed good sensory scores. Most snacks developed are tuber and cereal mixes, totally non-cereal-based snacks are very limited in the market. Elephant foot yam (EFY) is a tuber crop developed in Africa, Asia, parts of South America, and the Caribbean and South Pacific islands. Yams are an astounding wellspring of dietary vitality for the vast majority in the developing nations (Krishnan et al., 2010). They are wealthy in minerals like phosphorous, potassium, manganese and in vitamins. In West and Central Africa, yams are prepared into dry yam tubers/cuts and flour. The fundamental application for yam flour has been in bread items and bites. Some species of yam are likewise used for pharmaceutical preparations (Firdouse et al., 2012). Water chestnut (Eleocharis dulcis) is an edible water angiosperm and one of the important annual water warm season crops. Water chestnut is an important product in food industry because of its unique taste (Shafi et al., 2016). Water chestnut is used as a nerve tonic from time immemorial. The fruits are used as intestinal astringents, aphrodisiacs, antileprotics, for urinary discharges, fractures, sore throat, anemia, free radical scavenging activity, hepatoprotective activity, antitumor and antioxidant activity (Song et al., 2007).

Response surface methodology (RSM) is an excellent statistical design of experiments for standardized extrusion conditions. It is commonly used to collect data and give valid and objective conclusions (Lohan et al., 2020; Montgomery, 2006). RSM is a process to check the effect of various experimental designs, like extrusion parameters (temperature, screw speed, feed moisture) on the properties (bulk density, expansion ratio, water solubility index and water absorption index) of an extruded snack in a simplified manner (Myers et al., 2016; Whitcomb \& Anderson, 2004). Screw speed and feed rate were found to have the least impact on extrudate properties (Anand \& Pavuluri, 2009).

In this modern world, the demand of making novel foods is fulfilled by extrusion technology. Preservation and improvement of nutritional value of food during processing (Kaushik et al., 2017) has remained one of the most challenging tasks for researchers (Indumathi et al., 2015; Kaushik, Sachdeva, Arora, \& Gupta, 2015; Sachdeva et al., 2015). To make a healthy extruded snack, it is important to wisely select multiple raw materials to achieve a balance between protein and carbohydrates. Extrusion cooking is now one of the most researched arenas in the current era for health and nutrition and is likely to remain so for a long time. Therefore, a process of non-cereal-starch-based extruded product was optimized in this present study. 


\section{Materials and Methods}

\section{$2.1 \quad$ Materials}

Ingredients for the preparation of ready-to-eat snack food consisted of elephant foot yam, taro and water chestnut used for the present study was purchased from local markets of Solan, Himachal Pradesh, India. A fine part of the elephant foot yam, taro and water chestnut was scraped, washed, shredded into $1 \mathrm{~cm}^{3}$ cubes and dried in a mini tray drying oven (Maro Scientific Works Pvt. Ltd., New Delhi, India) for $48 \mathrm{~h}$ at $50{ }^{\circ} \mathrm{C}$. Dried cubes were milled using a roller-mill (Chopin Laboratory CD-1 mill, France). The flour was sieved through a sieve of $45 \mathrm{~mm}$ mesh size to obtain uniform particle size. The flour was then packed in an airtight plastic container for future use.

\section{$2.2 \quad$ Preparation of Sample}

For the preparation of non-cereal extruded product, different proportion of elephant foot yam, taro and water chestnut flours were used. First sample concentration was EYF 30\%, taro $40 \%$ and water chestnut $30 \%$, second sample concentration was EYF $40 \%$, taro $30 \%$ and water chestnut $30 \%$, third sample concentration was EYF $30 \%$, taro $30 \%$ and water chestnut $40 \%$ and fourth sample concentration was equal proportion of EYF, taro and water chestnut. In preliminary trails, the equal proportion extruded products showed superior texture and sensory qualities and were used for further trails.

\subsection{Extruder and extrusion cooking}

A co-rotating twin-screw extruder (G.L. Extrusion Systems, New Delhi, India) having a barrel with 2 electric band heaters and 2 water cooling jackets received the raw feed and a variable speed feeder was used. The central drive was provided with a $7.5 \mathrm{HP}$ motor (450 V, 3ph, 50 cycles) and a temperature sensor was fixed on the front die plate. The output shaft of the worm reduction gear had torque limiter cooling and the die plate of the die was fixed by a screw nut tightened by a distinct wrench. The programmed cutting blade was settled on a turning shaft. The twin-screw extruder was kept running for a set period of time to steady the set temperatures, and samples were then poured into the feed hopper and the feed rate was adjusted to $4.5 \mathrm{~kg} / \mathrm{h}$ for easy and nonchoking operation. The product was collected at the die end and packed in zip-locked packets for suitable storage.

\subsection{Experimental design}

Response surface methodology was applied to the experimental data using a commercial statistical package (Design-Expert software version 6.0.8) for the generation of response surface plots and optimization of process variables. A central composite experimental design was used to study the effect of independent variables on dependent variables. Twenty sets of experiments were performed considering three independent variables: feed moisture, temperature, and screw speed on the response variables such as expansion ratio, water solubility index, water-holding capacity, and bulk density. The average from three replicated values of each run was taken as response variable. For the statistical analysis, the numerical levels were standardized to $-1,0$ and +1 in table 1. The experimental design in terms of actual levels is given in table 2. Levels of variables were selected based on preliminary trials. The standard scores were fitted to a quadratic polynomial regression model for predicting individual $\mathrm{Y}$ responses by employing the least square technique (Myers et al., 2016).

The experimental design involved 21 experiments and numerical optimization was done by conveying the specific areas to each of the responses (expansion ratio was maximized, bulk density and hardness were minimized and water holding capacity and water solubility index were kept in the range). The adjusted $\mathrm{R}^{2}$ was used to measure goodness of fit. Three optimum formulations having desirability of 1 were determined for each non-cereal extrudate and validated the predicted and actual values of responses at the optimized conditions. The snack quality parameters were desirability function vs. expansion ratio, water solubility index, water holding capac- 
Extruded snacks prepared from non-cereal starch $\mid 299$

Table 1: Independent variables and their coded and actual values used for optimization

\begin{tabular}{llrrr}
\hline & & \multicolumn{3}{c}{ Level } \\
\cline { 3 - 5 } Factors & Units & -1 & 0 & 1 \\
\hline Feed Moisture & $\%$ & 15 & 18 & 21 \\
Temperature & ${ }^{\circ} \mathrm{C}$ & 130 & 150 & 170 \\
Screw speed & $\mathrm{RPM}$ & 120 & 140 & 160 \\
\hline
\end{tabular}

ity, hardness, and bulk density.

The optimum feed rate was $18.22 \%$, Barrel temperature was $155.96^{\circ} \mathrm{C}$, Screw speed $142.75 \mathrm{rpm}$ and desirability 0.76 . The least deviation in actual values of response against predicted values was found in the formulation presented in table 3.

\subsection{Evaluation of textural characteristics of extrudates}

\section{Expansion Ratio (ER)}

ER was determined by the method of (Ryu \& Ng, 2001). The diameter of extrudates was measured at ten different positions along the length of each sample using a digital vernier caliper. The ER of extrudates was calculated as equation 1 :

$$
\text { Expansion ratio }=\frac{\text { Extrudate diameter }}{\text { Die diameter }}
$$

\section{Water solubility index (WSI)}

Water solubility indexes of samples were determined according to the method described by Kaushik, Sachdeva, Arora, and Gupta (2015). Sample $(2.5 \mathrm{~g})$ was dispersed in $30 \mathrm{ml}$ of distilled water using a glass rod and cooked at 90 ${ }^{\circ} \mathrm{C}$ for $15 \mathrm{~min}$ in a water bath. The cooked paste was cooled to room temperature and centrifuged at $3000 \times \mathrm{g}$ for $10 \mathrm{~min}$. The supernatant was decanted into a tarred evaporating dish to determine its solid content. The weight of the dried solids was recovered by evaporating the supernatant for $4 \mathrm{~h}$ at $110^{\circ} \mathrm{C}$. The WSI was calculated as equation 2 :

$$
\mathrm{WSI}=\frac{W S}{W D S} \times 100
$$

Where,

WS: weight of dissolved solids in supernatant WDS: weight of dry solids.

\section{Water holding capacity (WHC)}

Water holding capacities of samples were determined according to the method described by Kaushik et al. (2018). Water holding capacity was determined by mixing $1 \mathrm{~g}$ of sample with $15 \mathrm{ml}$ deionized water in pre-weighed centrifuge tubes. After holding for $30 \mathrm{~min}$, the tubes were centrifuged for $10 \mathrm{~min}$ at $3000 \times \mathrm{g}$. The supernatant was discarded, and tubes were then weighed again. Water holding capacity was expressed as $\mathrm{g}$ of water retained per $\mathrm{g}$ of sample. The WHC was calculated as equation 3 :

$$
\mathrm{WHC}=\frac{\text { Fresh residue }- \text { Dry residue }}{\text { Dry Residue }} \times 100
$$

\section{Hardness}

The hardness of extruded snacks was measured using a TMS Texture Analyzer (Food Technology Corporation, Sterling, Virginia, USA) equipped with a $1000(\mathrm{~N})$ load cell, and a $0.05(\mathrm{~N})$ detection range.

\section{Bulk density (BD)}

The bulk density was calculated by measuring the actual dimensions of the extrudates. The diameter of the extrudates was measured with a vernier caliper and the lengths per unit weight (grams) of the samples were determined (Kaur \& Singh, 2005). The BD of the extrudates was calculated as equation 4 :

$$
Q_{d}=\frac{4}{\Pi d^{2} l}
$$

IJFS | October 2021 | Volume $10 \mid$ pages 296-310 
300 | Saklani et al.

Table 2: Experimental design and results of the central composite design of 20 experiments

\begin{tabular}{|c|c|c|c|c|c|c|c|c|}
\hline $\begin{array}{l}\text { Sr. } \\
\text { No. }\end{array}$ & $\begin{array}{c}\text { Feed } \\
\text { Moisture (\%) }\end{array}$ & $\begin{array}{l}\text { Temperature } \\
\left({ }^{o} \mathrm{C}\right)\end{array}$ & $\begin{array}{l}\text { Screw speed } \\
(\mathrm{rpm})\end{array}$ & $\begin{array}{l}\text { Expansion } \\
\text { Ratio }\end{array}$ & $\begin{array}{l}\text { Water solubility } \\
\text { index }(\%)\end{array}$ & $\begin{array}{l}\text { Water holding } \\
\text { capacity }(\mathrm{g} / \mathrm{g})\end{array}$ & $\begin{array}{l}\text { Hardness } \\
(\mathrm{N})\end{array}$ & $\begin{array}{c}\text { Bulk Density } \\
\left(\mathrm{g} / \mathrm{cm}^{3}\right)\end{array}$ \\
\hline 1 & 15 & 170 & 120 & $2.65 \pm 0.56^{a}$ & $28.19 \pm 1.26^{a}$ & $5.72 \pm 1.75^{a}$ & $62.45 \pm 2.49^{a}$ & $0.26 \pm 0.03^{a}$ \\
\hline 2 & 21 & 170 & 160 & $3.09 \pm 0.73^{a}$ & $29.34 \pm 1.36^{a b}$ & $6.19 \pm 1.56^{a}$ & $60.23 \pm 2.66^{a b}$ & $0.28 \pm 0.04^{a}$ \\
\hline 3 & 21 & 130 & 120 & $2.79 \pm 0.51^{a}$ & $29.74 \pm 1.34^{a b}$ & $5.71 \pm 1.62^{b}$ & $52.19 \pm 2.13^{a b}$ & $0.25 \pm 0.03^{a}$ \\
\hline 4 & 21 & 130 & 160 & $3.13 \pm 0.75^{a b}$ & $30.55 \pm 1.24^{a}$ & $6.04 \pm 1.52^{b}$ & $51.63 \pm 2.19^{a}$ & $0.29 \pm 0.04^{a}$ \\
\hline 5 & 15 & 130 & 120 & $2.69 \pm 0.61^{a}$ & $28.89 \pm 1.19^{b}$ & $5.81 \pm 1.67^{a b}$ & $50.46 \pm 2.28^{b a}$ & $0.27 \pm 0.02^{a}$ \\
\hline 6 & 18 & 150 & 140 & $2.72 \pm 0.59^{a}$ & $28.17 \pm 1.28^{a}$ & $6.08 \pm 1.50^{a}$ & $54.63 \pm 2.06^{a b}$ & $0.26 \pm 0.03^{a}$ \\
\hline 7 & 15 & 150 & 140 & $2.84 \pm 0.65^{a}$ & $30.53 \pm 1.36^{a}$ & $5.96 \pm 1.67^{a}$ & $53.47 \pm 2.14^{b a}$ & $0.25 \pm 0.02^{a b}$ \\
\hline 8 & 18 & 170 & 150 & $3.12 \pm 0.71^{a b}$ & $30.16 \pm 1.51^{a}$ & $5.89 \pm 1.43^{a}$ & $63.13 \pm 2.42^{a}$ & $0.29 \pm 0.03^{a}$ \\
\hline 9 & 21 & 150 & 140 & $3.19 \pm 0.76^{a b}$ & $30.94 \pm 1.42^{a}$ & $6.13 \pm 1.68^{a b}$ & $54.74 \pm 2.15^{b}$ & $0.28 \pm 0.03^{a}$ \\
\hline 10 & 18 & 170 & 130 & $3.13 \pm 0.69^{b}$ & $29.47 \pm 1.19^{a b}$ & $6.24 \pm 1.54^{b}$ & $61.19 \pm 2.49^{b}$ & $0.24 \pm 0.02^{a}$ \\
\hline 11 & 18 & 150 & 140 & $2.75 \pm 0.61^{a}$ & $30.67 \pm 1.29^{b}$ & $5.64 \pm 1.47^{a b}$ & $55.74 \pm 2.43^{a}$ & $0.26 \pm 0.02^{a b}$ \\
\hline 12 & 21 & 170 & 120 & $2.66 \pm 0.58^{a}$ & $29.45 \pm 1.31^{b}$ & $6.19 \pm 1.69^{a}$ & $62.37 \pm 2.63^{a}$ & $0.27 \pm 0.03^{a}$ \\
\hline 13 & 18 & 150 & 140 & $2.56 \pm 0.55^{a}$ & $30.13 \pm 1.36^{a b}$ & $5.96 \pm 1.57^{a}$ & $56.15 \pm 2.84^{a b}$ & $0.26 \pm 0.02^{a}$ \\
\hline 14 & 17 & 150 & 140 & $2.87 \pm 0.59^{a b}$ & $30.43 \pm 1.41^{b}$ & $5.92 \pm 1.43^{a}$ & $56.34 \pm 2.61^{b a}$ & $0.24 \pm 0.04^{a}$ \\
\hline 15 & 16 & 130 & 160 & $3.18 \pm 0.74^{a}$ & $29.32 \pm 1.23^{a b}$ & $5.73 \pm 1.39^{a b}$ & $51.63 \pm 2.55^{a}$ & $0.26 \pm 0.02^{a b}$ \\
\hline 16 & 15 & 170 & 160 & $2.84 \pm 0.66^{a b}$ & $29.41 \pm 1.54^{a b}$ & $6.12 \pm 1.77^{b}$ & $60.98 \pm 2.23^{a b}$ & $0.28 \pm 0.02^{a b}$ \\
\hline 17 & 15 & 150 & 130 & $3.05 \pm 0.72^{b}$ & $28.94 \pm 1.35^{a b}$ & $6.22 \pm 1.62^{b}$ & $54.36 \pm 2.47^{b a}$ & $0.24 \pm 0.03^{a}$ \\
\hline 18 & 18 & 150 & 140 & $2.86 \pm 0.67^{a b}$ & $29.23 \pm 1.14^{a}$ & $6.11 \pm 1.58^{a b}$ & $53.87 \pm 2.61^{a}$ & $0.25 \pm 0.03^{a}$ \\
\hline 19 & 18 & 150 & 140 & $2.73 \pm 0.69^{a}$ & $29.56 \pm 1.16^{a}$ & $5.96 \pm 1.55^{a}$ & $54.13 \pm 2.39^{a b}$ & $0.24 \pm 0.02^{a}$ \\
\hline 20 & 18 & 130 & 160 & $3.17 \pm 0.76^{a}$ & $30.21 \pm 1.19^{a}$ & $5.81 \pm 1.49^{a}$ & $50.76 \pm 2.45^{a}$ & $0.26 \pm 0.03^{a}$ \\
\hline \multicolumn{4}{|c|}{ Regression } & \multicolumn{5}{|c|}{ Sum of squares } \\
\hline \multicolumn{4}{|c|}{ Standard deviations } & 0.20 & 0.43 & 0.14 & 1.12 & 0.015 \\
\hline \multicolumn{4}{|c|}{$P$ value } & 0.001 & 0.001 & 0.001 & 0.001 & 0.001 \\
\hline \multicolumn{4}{|c|}{ Adequate precision } & 3.84 & 8.874 & 9.311 & 14.772 & 4.952 \\
\hline \multicolumn{4}{|c|}{$\mathrm{R}^{2}$} & 0.853 & 0.844 & 0.805 & 0.951 & 0.822 \\
\hline \multicolumn{4}{|c|}{ Adjusted $\mathrm{R}^{2}$} & 0.651 & 0.703 & 0.629 & 0.908 & 0.682 \\
\hline \multicolumn{4}{|c|}{ Lack of fit } & 1.23 & 1.31 & 1.68 & 2.01 & 2.37 \\
\hline \multicolumn{4}{|c|}{$\mathrm{CV}(\%)$} & 6.77 & 1.44 & 2.43 & 0.60 & 5.85 \\
\hline
\end{tabular}

Data are presented as means \pm SEM $(\mathrm{n}=3)$

${ }^{a-d}$ Means within a column with different lowercase superscript are significantly different $(\mathrm{p}<0.05)$ from each other

Where,

$\mathrm{Q}_{d}=$ bulk density $(\mathrm{g} / \mathrm{cm} 3)$,

$\mathrm{d}=$ diameter of the extrudate $(\mathrm{cm})$,

$\mathrm{l}=$ lengths per $\mathrm{g}$ of the extrudate $(\mathrm{cm} / \mathrm{g})$

\section{Statistical analysis}

The optimization of product was carried out using Design-Expert software version 6.0.8, however, Microsoft excel, 2014 (Microsoft Corp., Redmond, WA) was used for the calculation of standard error of the mean (SEM). Statistical difference in terms of significant and nonsignificant values was confirmed by one- and twoway analysis of variance and comparison among means was completed by critical difference values (Kaushik, Sachdeva, \& Arora, 2015).

\section{Results and Discussion}

Independent variables and their coded and actual values used for optimization are summarized in table 1 . The data on mean values of physical properties of extruded products along with their standard deviations are summarized in table 2. ANOVA and regression coefficients are summarized in tables 2 and 3, respectively. Models for all parameters were significant, and all parameters were significantly affected by feed moisture, screw speed and temperature. All parameters showed high adequate precision in table 3 . Figure 1,2, 3 and 4 shows the effect of independent variables on the extrusion behavior and product characteristics. 
Extruded snacks prepared from non-cereal starch |301
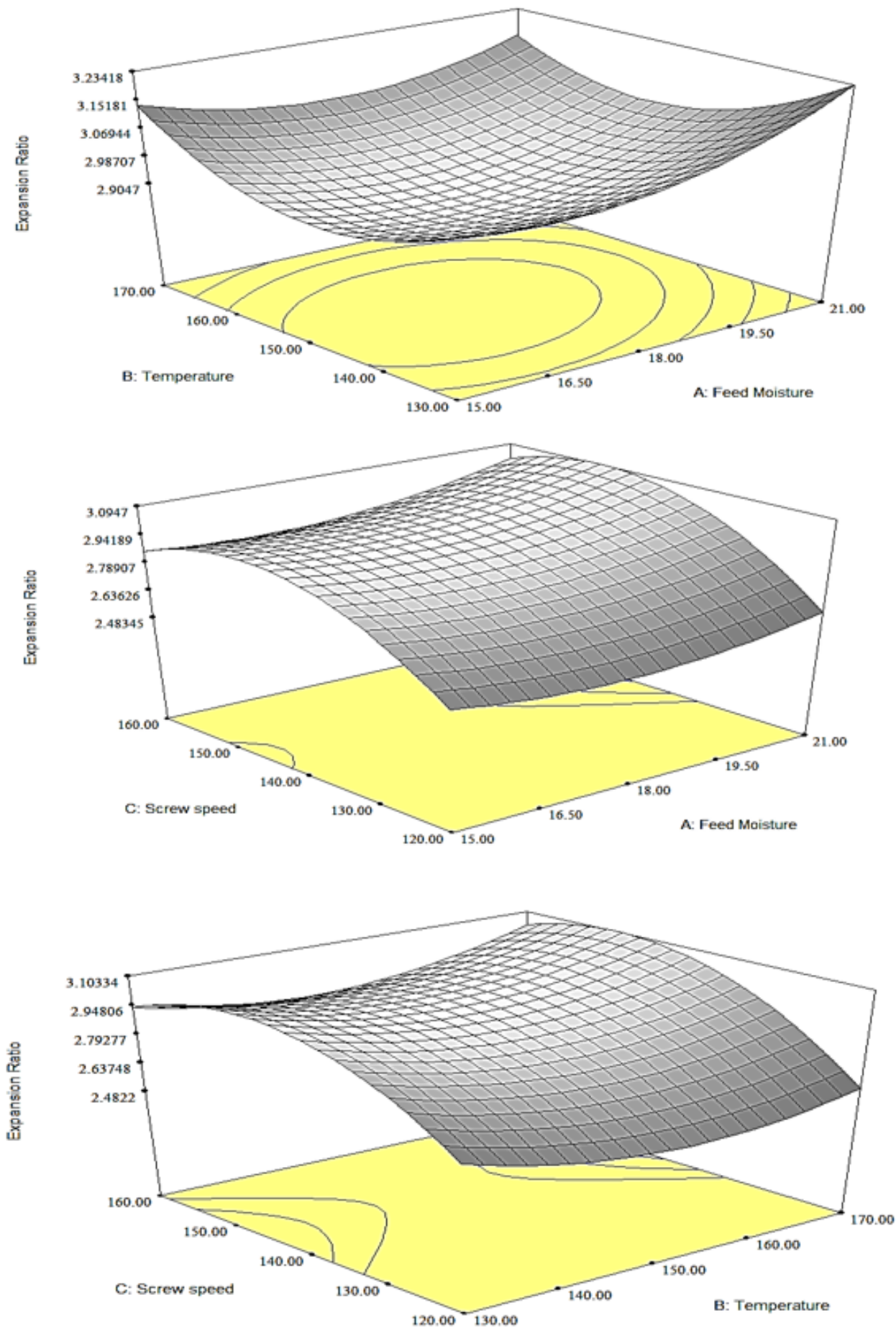

Figure 1: Effect of moisture, screw speed and temperature on expansion ratio

IJFS | October 2021 | Volume $10 \mid$ pages 296-310 
302 Saklani et al.
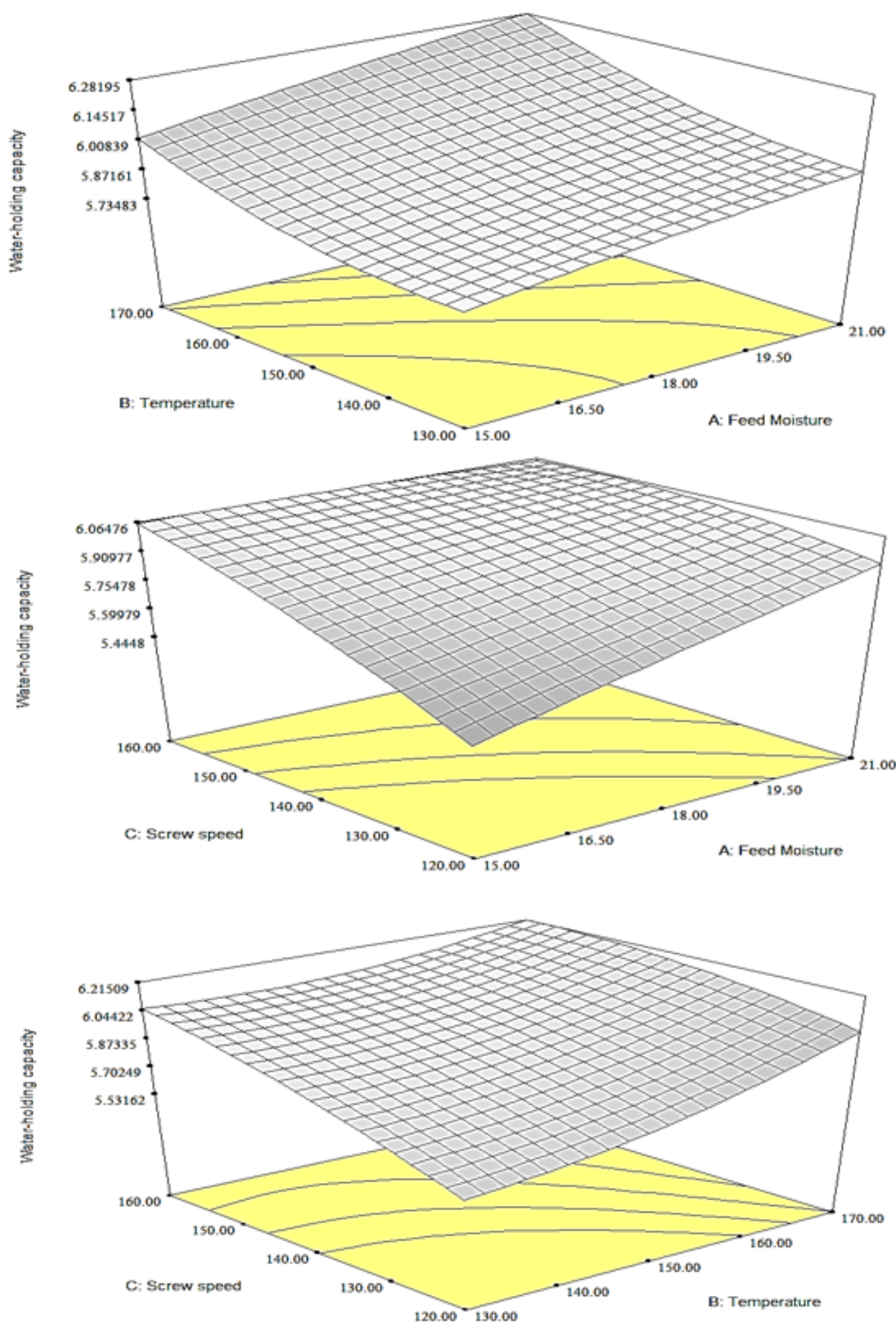

Figure 2: Effect of moisture, screw speed and temperature on water holding capacity

IJFS | October 2021 | Volume 10 | pages 296-310 
Extruded snacks prepared from non-cereal starch | 303
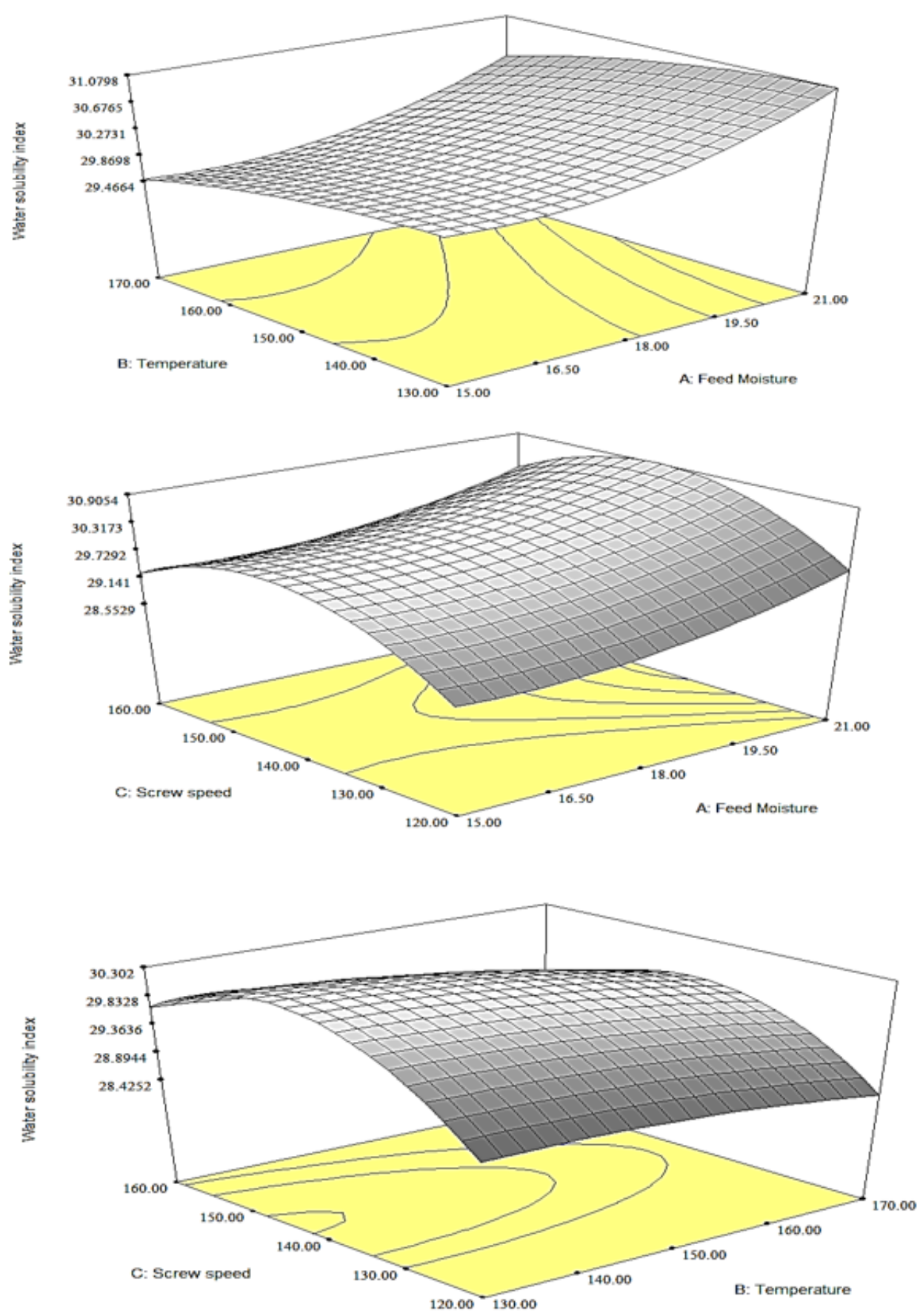

Figure 3: Effect of moisture, screw speed and temperature on water solubility index

IJFS | October 2021 | Volume $10 \mid$ pages 296-310 
304 | Saklani et al.
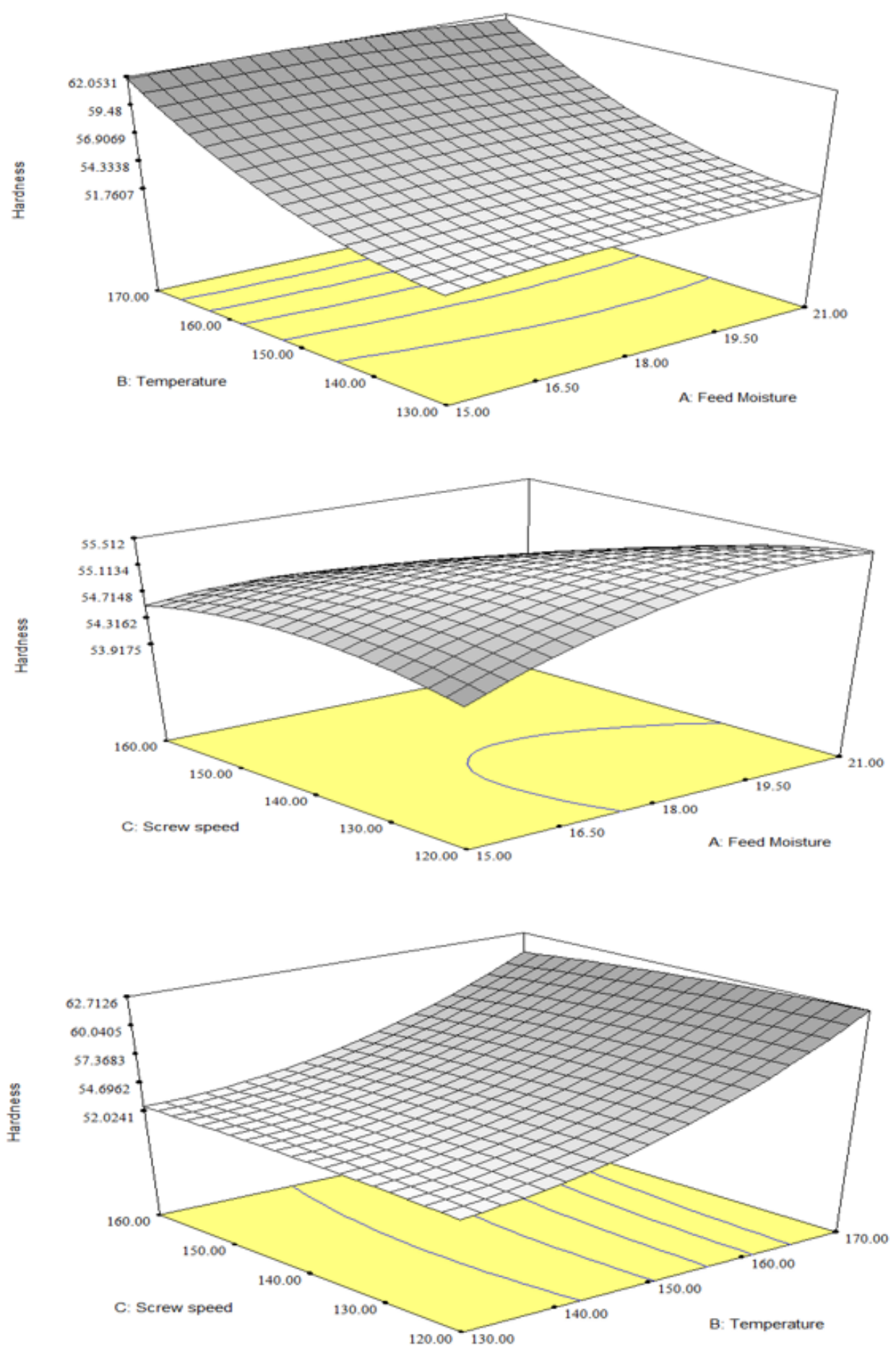

Figure 4: Effect of moisture, screw speed and temperature on hardness

IJFS | October $2021 \mid$ Volume 10 | pages 296-310 
Extruded snacks prepared from non-cereal starch | 305

Table 3: Regression coefficients for fitted models

\begin{tabular}{|c|c|c|c|c|c|}
\hline \multirow[b]{2}{*}{ Parameters } & \multicolumn{5}{|c|}{ Regression coefficients } \\
\hline & ER & WSI & WHC & Hardness & $\mathrm{BD}$ \\
\hline Feed Moisture $\left(x_{1}\right)$ & $-0.30 * *$ & $-1.07^{*}$ & $+0.32^{*}$ & $+0.11^{* *}$ & $+2.20^{*}$ \\
\hline Temperature $\left(x_{2}\right)$ & $-0.10^{*}$ & $+0.12^{*}$ & $-0.02 *$ & $+4.76^{*}$ & $-3.97^{n} s$ \\
\hline Screw speed $\left(x_{3}\right)$ & $+0.15^{* * *}$ & $+0.79^{* *}$ & $+0.11^{*}$ & $-0.38^{*}$ & $+0.01 *$ \\
\hline Feed Moisture $^{2}\left(x_{1}\right)^{2}$ & $+0.01^{* *}$ & $+0.03^{* *}$ & $-1.17^{*}$ & $-0.34^{*}$ & $+1.20^{*}$ \\
\hline Temperature $^{2}\left(x_{2}\right)^{2}$ & $+3.53^{*}$ & $-3.28^{n s}$ & $+1.85^{*}$ & $+2.05^{*}$ & $+1.00^{*}$ \\
\hline Screw speed ${ }^{2}\left(x_{3}\right)^{2}$ & $-6.22^{n s}$ & $-2.56^{*}$ & $-1.26^{*}$ & $-0.28^{*}$ & $-4.20^{n s}$ \\
\hline Feed Moisture $\times$ Temperature $\left(x_{1} \times x_{2}\right)$ & $-7.08^{n s}$ & $-1.25^{*}$ & +2.50 & $-0.29 *$ & $-6.25^{n s}$ \\
\hline Feed Moisture $\times$ Screw speed $\left(x_{1} \times x_{3}\right)$ & $+4.58 *$ & $-6.25^{n s}$ & -2.04 & $-0.41 * * *$ & $-2.29 *$ \\
\hline Temperature $\times$ Screw speed $\left(x_{2} \times x_{3}\right)$ & $+1.06^{*}$ & $-3.00^{n s}$ & -2.00 & $-0.58^{*}$ & $+1.56^{*}$ \\
\hline
\end{tabular}

Level of significance: ${ }^{*} \mathrm{P}<0.1,{ }^{* *} \mathrm{P}<0.05,{ }^{* * *} \mathrm{P}<0.01$, ns non-significant

\subsection{Expansion Ratio (ER)}

Expansion ratio as an index of puffing level is one of the most significant physical characteristics of the extrudates. ER values for the extrudates ranged between 2.56 and 3.18 (table 1; Figure $1)$. The responses were analyzed using ANOVA and the data are presented in table $1 \mathrm{~b}$. The regression model had a coefficient of determination $\left(\mathrm{R}^{2}\right)$ and adjusted $\mathrm{R}^{2}$ value of 0.853 and 0.651 , respectively. The CV was found to be $6.77 \%$. Similar results were reported by Ganorkar and Jain (2015) who found the same pattern for ER in extrusion cooking of maize grits at $150-160{ }^{\circ} \mathrm{C}$ product temperature and $47-60 \mathrm{~kg} / \mathrm{h}$ feed rate. Dogan and Karwe (2003) reported similar results in the extrusion of quinoa at $130-170{ }^{\circ} \mathrm{C}, 250-500$ $\mathrm{rpm}$ screw speed and $300 \mathrm{~g} / \mathrm{min}$ feed rate.

$$
\begin{aligned}
& \text { ER Coded Factors }= \\
& 0.50\left(x_{1}\right)+2.05-003\left(x_{2}\right)+0.18\left(x_{3}\right) \\
& +0.09\left(x_{1}\right)^{2}+0.14\left(x_{2}\right)^{2}-0.25\left(x_{3}\right)^{2} \\
& +0.042\left(x_{1} \times x_{2}\right)+0.028\left(x_{1} \times x_{3}\right) \\
& +0.043\left(x_{2} \times x_{3}\right)
\end{aligned}
$$

\subsection{Water solubility index (WSI)}

WSI values for the extrudates ranged between 28.19 and $30.94 \%$ (table 1). The responses were analyzed using ANOVA and the data are presented in table 2 and Figure 2. The regression model had a coefficient of determination $\left(\mathrm{R}^{2}\right)$ and adjusted $R^{2}$ value of 0.844 and 0.703 , respectively. The CV was found to be $1.44 \%$. The negative coefficient of the linear term moisture (table 2) indicated that WSI decreased, while positive coefficients of the linear terms screw speed and temperature indicated that WSI increased with the increase in variables. Extrusion at low moisture might result in increases in water-soluble molecules (da Silva et al., 2009). Higher WSI of extrudates was reported with decreasing screw speed (Pardhi et al., 2019). Increasing temperature would increase the degree of starch gelatinization that could increase the quantity of soluble starch resulting in an increase in WSI. The increase in WSI with increasing screw speed was consistent with the results reported by Sebio and Chang (2000).

$$
\begin{aligned}
& \text { WSI Coded Factors }= \\
& 0.48\left(x_{1}\right)-0.31\left(x_{2}\right)+0.30\left(x_{3}\right)+0.34\left(x_{1}\right)^{2} \\
& -0.13\left(x_{2}\right)^{2}-1.03\left(x_{3}\right)^{2}-7.50-03\left(x_{1} \times x_{2}\right) \\
& -0.38\left(x_{1} \times x_{3}\right)-0.12\left(x_{2} \times x_{3}\right)
\end{aligned}
$$

\subsection{Water holding capacity (WHC)}

WHC values for the extrudates ranged between 4.06 and $5.0 \mathrm{~g} / \mathrm{g}$ (table 1 ). The responses were analyzed using ANOVA and the data are pre- 
sented in table 2 . The regression model had a coefficient of determination $\left(\mathrm{R}^{2}\right)$ and adjusted $\mathrm{R}^{2}$ value of 0.805 and 0.629 , respectively. The $\mathrm{CV}$ was found to be $2.43 \%$. Increase in feed moisture resulted in a significant increase in WHC. It is worth noting that starch granules must undertake a certain degree of conversion to initiate water absorption (Filli et al., 2013). The negative coefficients of the linear terms screw speed and temperature (table 2; Figure 3) indicated that WHC decreases with increases in these variables. It could be expected that more undamaged polymer chains and a greater availability of hydrophilic groups, which could bind more water, resulted in higher values of WHC under low shear conditions with lower screw speed. Higher temperature increased degradation and dextrinization of starch. A negative effect of temperature and screw speed on WHC was also reported by Altan et al. (2008) in barley tomato pomace blend-based extrudates.

$$
\begin{aligned}
& \text { WHC Coded Factors }= \\
& 0.12\left(x_{1}\right)+0.16\left(x_{2}\right)+0.18\left(x_{3}\right)-0.011\left(x_{1}\right)^{2} \\
& +0.074\left(x_{2}\right)^{2}-0.051\left(x_{3}\right)^{2}+0.015\left(x_{1} \times x_{2}\right) \\
& -0.12\left(x_{1} \times x_{3}\right)-0.080\left(x_{2} \times x_{3}\right)
\end{aligned}
$$

\subsection{Hardness}

The hardness is the highest force mandatory for a probe to penetrate the extrudates. Hardness can be determined by the availability of hydrophilic groups and capacity of gel formation of the macromolecule (Gomez \& Aguilera, 1983). Hardness values for the extrudates ranged between 50.46 and $63.13(\mathrm{~N})$ (table 2). The responses were analyzed using ANOVA and the data are presented in table 2 . The regression model had a coefficient of determination $\left(\mathrm{R}^{2}\right)$ and adjusted $\mathrm{R}^{2}$ value of 0.951 and 0.908 , respectively. The CV was found to be $0.60 \%$. Increase in feed moisture resulted in a significant increase in hardness. When the moisture content of feed increased while keeping blend ratio constant, hardness increased (Jha \& Prasad, 2003). Hardness can decrease because an increase in the barrel temperature will increase the degree of superheating of water in the extruder, encouraging bubble formation and also decreasing the viscosity of melt (Pardhi et al., 2019).

$$
\begin{aligned}
& \text { Hardness Coded Factors }= \\
& 3.08\left(x_{1}\right)-1.00\left(x_{2}\right)+0.51\left(x_{3}\right)-0.03\left(x_{1}\right)^{2} \\
& +5.12-03\left(x_{2}\right) 2-6.96-04\left(x_{3}\right)^{2}-4.85 \\
& -03\left(x_{1} \times x_{2}\right)-6.77-03\left(x_{1} \times x_{3}\right) \\
& -1.45-03\left(x_{2} \times x_{3}\right)
\end{aligned}
$$

\subsection{Bulk density (BD)}

The density of extrudates varied between 0.24 and $0.29 \mathrm{~g} / \mathrm{cm}^{3}$ (table 1). ANOVA for the model as fitted (table 4$)$ shows high significance $(\mathrm{P}<$ $0.001)$ with a correlation coefficient $\left(\mathrm{R}^{2}\right)$ and adjusted $\mathrm{R}^{2}$ value of 0.822 and 0.682 , respectively. The CV was found to be $5.85 \%$ indicating that experimental data were acceptably explained. The BD increased significantly with the increase in feed moisture content (table 2). The high dependence of $\mathrm{BD}$ and expansion on feed moisture would reflect on elasticity characteristics of the starch-based material (Hagenimana et al., 2006). The bulk density was significantly influenced by temperature, screw speed, and water content (Pardhi et al., 2019). Moisture is critical in starch gelatinization, protein denaturation, barrel lubrication and final product quality. A dry extruder can process materials with $8-22 \%$ moisture with no additional drying of extrudates. Most extrudate snacks have a moisture content between $8-12 \%$ and require additional drying to impart the desired texture and mouthfeel (Navel \& Thakor, 2015).

$$
\begin{aligned}
& \text { BD Coded Factors }= \\
& 6.22-03\left(x_{1}\right)+2.00-03\left(x_{2}\right)+6.55-03\left(x_{3}\right) \\
& +0.01\left(x_{1}\right)^{2}+4.014-03\left(x_{2}\right)^{2}-0.017\left(x_{3}\right)^{2} \\
& -3.75-03\left(x_{1} \times x_{2}\right)-0.014\left(x_{1} \times x_{3}\right) \\
& +6.25-03\left(x_{2} \times x_{3}\right)
\end{aligned}
$$

Pardhi et al. (2019) standardized the processing parameters of brown rice grits. They reported water solubility index (5.43 to $14.32 \%)$, water absorption index (4.72 to 7.81 ), and bulk 
Extruded snacks prepared from non-cereal starch $\mid 307$

Table 4: Expected and observed values for product responses at optimized processing conditions

\begin{tabular}{lccccc}
\hline Parameter & $\begin{array}{c}\text { Expansion } \\
\text { Ratio }\end{array}$ & $\begin{array}{c}\text { Bulk density } \\
(\mathrm{g} / \mathrm{cc})\end{array}$ & $\begin{array}{c}\text { Water holding } \\
\text { capacity (g/g) }\end{array}$ & $\begin{array}{c}\text { Water Solubility } \\
\text { index (\%) }\end{array}$ & $\begin{array}{c}\text { Hardness } \\
(\mathbf{N})\end{array}$ \\
\hline \multicolumn{7}{c}{ \# Non-cereals in Combination } \\
\hline Expected Value & 2.90 & 0.27 & 5.97 & 29.55 & 56.78 \\
Observed value & 2.81 & 0.26 & 5.83 & 28.47 & 55.62 \\
CV $(\%)$ & 6.77 & 5.85 & 2.42 & 1.44 & 0.60 \\
\hline
\end{tabular}

Data are presented as means \pm SEM $(\mathrm{n}=3)$

density $(0.065$ to $0.188 / \mathrm{ml})$. They also reported that with increases in moisture, bulk density, water absorption index and hardness increased, while water solubility indexes decreased; increased temperature, on the other hand, decreased all parameters. (Thymi et al., 2005) utilized tuber starch for the development of extrudates and studied their various physical properties, including bulk density, true density, porosity, expansion ratio, water holding capacity and water solubility index. The influence of process variables on physical properties has been shown to be generally significant in all these studies.

\section{Conclusion}

The physical properties of elephant foot yam, taro and water chestnut snacks were highly influenced by processing parameters. Lower as well as higher levels of feed moisture and extrusion temperature were found to be critical with respect to expansion and density of snacks. The extruded snacks prepared at optimized processing conditions displayed better physical and functional properties. Elephant foot yam, taro and water chestnut flour, all rich sources of phytochemicals, could be used as functional ingredients in the development of nutritious and healthy extruded snacks. The developed snacks can be consumed even during fasts by the Indian population. The equal ratio of all three ingredients was optimized for snack production.

\section{Acknowledgements}

This work was conducted in the School of Bioengineering and Food Technology, Shoolini Uni- versity, Solan, Himachal Pradesh. All chemicals, glassware and Instruments were provided by the School of Bioengineering and Food Technology, Shoolini University, Solan, Himachal Pradesh.

\section{References}

Altan, A., McCarthy, K. L., \& Maskan, M. (2008). Evaluation of snack foods from barley-tomato pomace blends by extrusion processing. Journal of Food Engineering, 84 (2), 231-242. https: / / doi. org/10.1016/j.jfoodeng.2007.05.014

Anand, P. P., \& Pavuluri, S. R. (2009). Development of extruded snacks from low value fish using twin screw extruder. American society of agricultural and biological engineer's annual international meeting, 2009, 1.

Anuj Saklani, P. C. N. K., Ravinder Kaushik, \& Kumar, M. (2021). Effect of taro (colocasia esculenta) enrichment on physicochemical and textural properties of cake. International Journal of Food Studies, SI14-SI25. https : / / doi.org / 10.7455 / ijfs/10.SI.2021.a2

Balfour, D., Sonkar, C., Sharma, S., et al. (2014). Development and quality evaluation of extruded fortified corn snack. International Journal of Food and Nutritional Sciences, 3(4), 60.

Bordoloi, R., \& Ganguly, S. (2014). Extrusion technique in food processing and a review on its various technological parameters. Indian Journal of Scientific Research and Technology, 2(1), 1-3.

IJFS | October 2021 | Volume $10 \mid$ pages 296-310 
da Silva, M. C., Piler de Carvalh, C. W., \& Andrade, C. T. (2009). The effects of water and sucrose contents on the physicochemical properties of non-directly expanded rice flour extrudates. Ciencia $E$ Tecnologia De Alimentos, 29(3), 661666. https:// doi.org/10.1590/S010120612009000300032

Deshpande, H. W., \& Poshadri, A. (2011). Physical and sensory characteristics of extruded snacks prepared from foxtail millet based composite flours. International food research journal, $18(2)$.

Dogan, H., \& Karwe, M. V. (2003). Physicochemical properties of quinoa extrudates. Food Science and Technology International, 9(2), 101-114. https://doi. org $/ 10.1177 / 108201303033940$

Filli, K. B., Nkama, I., Jideani, V. A., \& Ibok, I. U. (2013). Effect of process variables on the hydration properties and acceptability of extruded millet-soybean blends for fura manufacture. British Food Journal, 115(6), 884-898. https:// doi.org/ 10.1108/BFJ-May-2010-0091

Firdouse, S., Gupta, J., Alam, P., Firdouse, A., Naaz, F., \& Durrani, M. (2012). Pharmacognostic evaluation of amorphophallus campanulatus tubers. International Journal of Pharmacy \& Life Sciences, 3(12).

Ganorkar, P. M., \& Jain, R. K. (2015). Development of flaxseed fortified rice-corn flour blend based extruded product by response surface methodology. Journal of Food Science and Technology MYSORE, 52(8), 5075-5083. https:// doi.org/10.1007/s13197-014-1541-1

Gomez, M. H., \& Aguilera, J. M. (1983). Changes in the starch fraction during extrusioncooking of corn. Journal of Food Science, 48(2), 378-381. https: / / doi.org / 10 . 1111/j.1365-2621.1983.tb10747.x

Hagenimana, A., Ding, X. L., \& Fang, T. (2006). Evaluation of rice flour modified by extrusion cooking. Journal of Cereal Science, 43(1), 38-46. https://doi.org/10. 1016/j.jcs.2005.09.003

Indumathi, K. P., Kaushik, R., Arora, S., \& Wadhwa, B. K. (2015). Evaluation of iron fortified gouda cheese for sensory and physicochemical attributes. Journal of Food Science and Technology MYSORE, 52(1), 493-499. https://doi. org/10.1007/s13197-013-1006-y

Jha, S., \& Prasad, S. (2003). Studies on extrusion cooking of rice and mung blend with salt and sugar. Journal of Food Science and Technology-mysore, 40, 257-261. https: / / api . semanticscholar . org / CorpusID : 88868612

Kaur, M., \& Singh, N. (2005). Studies on functional, thermal and pasting properties of flours from different chickpea (cicer arietinum 1.) cultivars. Food Chemistry, 91(3), 403-411. https: / / doi .org / 10. 1016/j.foodchem.2004.06.015

Kaushik, R., Chawla, P., Kumar, N., Janghu, S., \& Lohan, A. (2018). Effect of premilling treatments on wheat gluten extraction and noodle quality. Food Science and Technology International, 24(7), 627636.

Kaushik, R., Chawla, P., Kumar, N., \& Kumar, M. (2017). Effect of pre-milling treatments on wheat flour quality. The Annals of the University Dunarea de Jos of Galati. Fascicle VI-Food Technology, 41(2), 141-152.

Kaushik, R., Sachdeva, B., \& Arora, S. (2015). Heat stability and thermal properties of calcium fortified milk. CYTA-Journal of Food, 13(2), 305-311. https://doi.org/ 10.1080/19476337.2014.971346

Kaushik, R., Sachdeva, B., Arora, S., \& Gupta, C. (2015). Effect of fat content on sensory and physico-chemical properties of laboratory-pasteurised calcium- and vitamin d-fortified mixture of cow and buffalo milk. International Journal of Dairy Technology, 68(1), 135-143. https://doi. org/10.1111/1471-0307.12166

Krishnan, J. G., Padmaja, G., Moorthy, S. N., Suja, G., \& Sajeev, M. S. (2010). Effect of pre-soaking treatments on the nutritional profile and browning index of sweet potato and yam flours. Innovative Food Science 85 Emerging Technologies, 11(2), 387-393. https : / / doi .org / 10 . $1016 /$ j.ifset.2010.01.010 
Extruded snacks prepared from non-cereal starch |309

Lohan, A., Kaushik, R., Bansal, V., \& Gandhi, K. (2020). Flax seeds and finger millet enriched functional rusk. International Journal of Food Studies, 9(1).

Ministry of Food Processing Industries. (2015). Strategy and action plan for food processing industries in India 2005. Vision 2015, 152-153.

Montgomery, D. C. (2006). Design and analysis of experiments. Technometrics, 48(1), 158-158. https://doi.org/10.1198/tech. 2006.s372

Moreno, C. R., Fernandez, P. C. R., Rodriguez, E. O. C., Carrillo, J. M., \& Rochin, S. M. (2018). Changes in nutritional properties and bioactive compounds in cereals during extrusion cooking. Extrusion of Metals, Polymers and Food Products, 104124.

Myers, R. H., Montgomery, D. C., \& AndersonCook, C. M. (2016). Response surface methodology: Process and product optimization using designed experiments. John Wiley \& Sons.

Navel, S. S. B., S.A. Baslingappa, \& Thakor, N. I. (2015). Extrusion cooking technology for foods: A review. Journal of Ready to Eat Food, 3(2), 66-80. http://jakraya.com/ journal/pdf/7-jrefArticle_1.pdf

Pardhi, S. D., Singh, B., Nayik, G. A., \& Dar, B. N. (2019). Evaluation of functional properties of extruded snacks developed from brown rice grits by using response surface methodology. Journal of the Saudi Society of Agricultural Sciences, 18(1), 7-16.

Parvathi, S., Umamaheshwari, S., \& Subbulakshmi, B. (2016). Development of value added food products from tropical tubers. International Journal of Food and Fermentation Technology, 6(1), 67-74.

Rodriguez-Miranda, J., Ruiz-Lopez, I. I., Herman-Lara, E., Martinez-Sanchez, C. E., Delgado-Licon, E., \& Vivar-Vera, M. A. (2011). Development of extruded snacks using taro (colocasia esculenta) and nixtamalized maize (zea mays) flour blends. $L W T$ - Food Science and Technology, 44(3, SI), 673-680. https: //doi.org/10.1016/j.lwt.2010.06.036
Ryu, G. H., \& Ng, P. K. W. (2001). Effects of selected process parameters on expansion and mechanical properties of wheat flour and whole cornmeal extrudates. Starch Starke, 53(3-4), 147-154. https:// doi. org / 10.1002/1521-379X(200104)53:3/ 4〈147::AID-STAR147〉3.0.CO;2-V

Sachdeva, B., Kaushik, R., Arora, S., \& Kapila, S. (2015). Bioavailability of iron in multiple fortified milk. Journal of Food Science and Technology - MYSORE, 52(9), 6017-6023. https:// doi.org/10.1007/ s13197-015-1711-9

Sebio, L., \& Chang, Y. K. (2000). Effects of selected process parameters in extrusion of yam flour (dioscorea rotundata) on physicochemical properties of the extrudates. Nahrung - Food, 44(2), 96-101. https: / / doi.org / 10.1002 / (SICI) 1521$3803(20000301) 44: 2\langle 96::$ AID-FOOD96 $\rangle$ 3.0.CO;2-9

Shafi, M., Baba, W. N., Masoodi, F. A., \& Bazaz, R. (2016). Wheat-water chestnut flour blends: Effect of baking on antioxidant properties of cookies. Journal of Food Science and Technology MYSORE, 53(12), 4278-4288. https:// doi.org/10.1007/s13197-016-2423-5

Singh, J., Kaur, L., McCarthy, O. J., Moughan, P. J., \& Singh, H. (2009). Development and characterization of extruded snacks from new zealand taewa (maori potato) flours. Food Research International, 42(5-6), 666-673. https:// doi. org/10.1016/j.foodres.2009.02.012

Song, M.-C., Yang, H.-J., Myun-Ho, B., Kim, D.-K., Jeong, T.-S., Kim, J.-P., \& Baek, N.-I. (2007). Antioxidant and antiatherogenic activity ofcis-hinokiresinol fromtrapa pseudoincisa. Archives of pharmacal research, 30(11), 1392.

Thymi, S., Krokida, M. K., Pappa, A., \& Maroulis, Z. B. (2005). Structural properties of extruded corn starch. Journal of Food Engineering, 68 (4), 519-526. https: //doi.org/10.1016/j.jfoodeng.2004.07. 002

Whitcomb, P. J., \& Anderson, M. J. (2004). Rsm simplified: Optimizing processes us- 
ing response surface methods for design of experiments. CRC press.

Yagci, S., \& Gogus, F. (2008). Response surface methodology for evaluation of physical and functional properties of extruded snack foods developed from foodby-products. Journal of Food Engineering, 86(1), 122-132. https://doi.org/10. 1016/j.jfoodeng.2007.09.018 